Article

\title{
Daily Positive Affect and Job Crafting: The Cross Level Moderating Effects of Individuals' Resources
}

\author{
Nayoung Kwon, Mihee Kim and Min-soo Kim * \\ School of Business, Hanyang University, Seoul 04763, Korea \\ * Correspondence: kimmin@hanyang.ac.kr; Tel.: +82-2-2220-2683
}

Received: 10 July 2019; Accepted: 6 August 2019; Published: 8 August 2019

\begin{abstract}
Whereas past research on daily job crafting has tended to focus on how job crafting affected employee behaviors, we extend this study by examining the antecedents of job crafting and cross-level moderators such as leader-member exchange (LMX) and resilience. Using experience-sampling methodology, we examined the within-person level relationship between positive affect and job crafting as well as the moderating role of individuals' LMX and resilience on this relationship. Finally, 105 employees completed surveys over 10 days. Results of hierarchical linear models revealed that daily positive affect was positively associated with job crafting. Also, results revealed moderating effects of LMX: the relation between positive affect and job crafting strengthened when employees had low-quality LMX relationship.
\end{abstract}

Keywords: job crafting; positive affect; LMX; resilience; ESM

\section{Introduction}

Nowadays, the considerably complex and uncertain environments surrounding modern organizations require employees to perform their tasks autonomously, actively making their own choices. Consistent with these trends, researchers are becoming gradually more interested in job crafting for employees in an organization [1]. Job crafting refers to the activities an individual initiates in order to utilize relationships or resources that had not been previously utilized, so as to give these resources meaning and assist another individual in performing given tasks [2]. In other words, job crafting refers to how employees use new resources and relationships to find meaning in the work they perform. Recent researchers have searched for the antecedents of job crafting, and, as a result, have verified the significant effects of various working conditions, individuals, and organizational characteristics [3,4]. Job crafting has typically been studied as an individual-level activity, but increasing research interest has also recently been shown in job crafting at the within-person level. Researchers have discovered that job crafting varies each day $[5,6]$. Thus, we conceptualized job crafting as a day-level phenomenon.

Although previous scholars highlighted daily job crafting, we know very little about the antecedents of daily job crafting at work. Thus, our study primarily focuses on how employees experience job crafting on a specific day. Building on affective event theory [7], we propose that daily affect fosters job crafting.

Meanwhile, some studies have been focused on the positive perspectives of organizational behavior on and the strengths of organizations and employees have been found [8]. Following this perspective, we tried to examine whether the daily positive affect can influence job crafting and whether employee characteristics can moderate that relation. Daily experience that occur in the workplace each day can differ based on the resources that employees possess [9]. That is to say, it is important to observe this phenomenon as members are expected to have different effects of experience depending on the level of resources they possess, even if they share similar daily experiences in the 
same workplace. The present study is aimed at verifying the moderating effect of the quality of the exchange relationship between leader and member (Leader Member Exchange Theory), a social resource that is the relationship linked to members as resources within an organization, and resilience, which is psychological resource, indicating the individual's ability to recover.

The contributions of the present study are significant. First, it showed that it is possible to enhance the understanding of job crafting by identifying an individual's daily positive affect as an antecedent of job crafting. The present study is particularly meaningful in that it used a methodology suitable for verifying the within-person level hypotheses. Second, the present study is significant because it examined the cross-level moderating effects on the relationship between daily positive affect and job crafting. In this study, we predicted that the relationship between daily positive affect and job crafting could be different, depending on LMX and resilience.

\section{Literature Review and Hypothesis Development}

\subsection{Relationship between Positive Affect and Job Crafting}

Job crafting means changing the nature or limit of the job through the active behavior of each member. In other words, it means creating changes and actively taking the lead in performing a task, rather than passively performing a given task $[10,11]$. Previous research has confirmed the relationship between job characteristics and job crafting. For example, Rudolph et al. [4] conducted a meta-analysis and showed that job autonomy and workload positively related to job crafting. Also, individual characteristics like proactive personality, and enjoyment of work have been found to enhance job crafting $[12,13]$.

Moreover, by defining job crafting in an organization as "daily" and "continuous" activities, many researchers propose that there is a need to conduct research on a daily basis [5,6]. Recently, increasing research on daily job crafting has defined job crafting as substantive behaviors that can be clearly shown and observed on a daily basis. Specifically, job crafting can include activities such as seeking advice from peers, seeking feedback on performance and performing challenging tasks [14]. Consistent with these previous studies, we would like to define job crafting as active behaviors that an individual exhibits daily in the workplace. Affective events theory enables one to explain how daily job crafting happens. Affective events theory describes that job characteristics influence specific work events. The event causes an emotional reaction, which leads to an action of employees [7]. In this regard, we propose that a positive affect may lead to job crafting.

Since positive affect is associated with energy, happiness, and passion, extremely positive employees have been found to perform a task delightfully, happily, and effectively [15]. Studies have found that positive affect is correlated with observable organizational citizenship behaviors, proactive behaviors, and task performance since the occurrence of positive reactions when performing a task can effectively determine behavioral tendencies $[16,17]$. Yet, these results of previous studies are not a validation of within-person level that can demonstrate the relationship between a positive affect and behavior [18]. In other words, it is limited because it simply shows the overall emotional tendencies that facilitate behaviors, and not the daily variability $[14,16,18]$. Therefore, the present study predicts that the relationship between daily positive affect and job crafting will be beneficial for the following reasons: first, when employees are in a positive mood, they feel more positive about their coworkers and establish better relationships; and second, a positive affect is able to take an approach perspective toward work [19-22]. Thus, employees are able to gain resources and reduce demands.

For a more in-depth understanding of this relationship, we have used the broad and build theory. According to this theory, positive affect can broaden thought-action repertoire and promote the use of personal resources [23]. For example, positive affect enables one to widen the array of thoughts and foster tasks to assimilate information. Thus, positive employees can be more proactive in achieving individual growth and expanding social connections. Therefore, we predict that having a daily positive 
affect will enable employees to tackle new challenges, actively seek necessary job resources such as motivation and relationship, and reduce unnecessary job demands. The following is our hypothesis:

Hypothesis 1 (H1). Daily positive affect will be positively related to job crafting.

\subsection{Moderating Effects of Individuals' Social and Personal Resources}

Employees experience events in an organization and perform their tasks every day. However, these daily activities may differ depending on factors such as the employees' abilities, interpersonal relationships, and personal tendencies [24]. Previous studies claim that resources are a valuable factor in explaining daily working life [5]. The present study aims to show how the moderators are related to the acquisition of resources. Specifically, we are going to look at the moderating effects of LMX, which is representative of inherent social resources that employees may have, and resilience, which is a psychological resource.

Leader-member exchange (LMX) is a social relationship that is formed between a leader and his or her subordinates [25]. Employees who have a low level of LMX, are unable to share social ties with their leaders or any "in-groups." Therefore, they receive neither emotional support from their leaders nor the sense of empowerment and responsibility needed to perform tasks. By contrast, employees who have high level of LMX possess external resources that help them succeed [26,27].

As mentioned, positive affect, represented by the happiness and joy of the employees occurring in the daily workplace, contributes to job crafting. When an individual routinely has few resources because of a low-level of LMX, their daily state which mean daily level of energy would be a strong impact on their job crafting. In this regard, we expect that the relationship between daily positive affect and daily job crafting will be stronger in employees with a lower level of LMX.

Hypothesis 2a (H2a). The relation of daily positive affect with job crafting will be stronger when LMX is low (vs. high).

Resilience is a personality characteristic associated with psychological resources. Resilience is the ability to recover from negative situations or events [28]. It involves growing and developing while simultaneously overcoming challenges [8]. Therefore, those with low resilience are unable to control their job stress as effectively as those who are highly resilient [29]; when confronted with situations or events that can lead to stress, those with low resilience would saturate much quicker. For employees with high resilience, however, it serves as a significant internal resource. In the present study, similar to LMX, the job crafting of employees with low resilience is more significantly influenced by their daily positive affect. Taken together, we hypothesize the following cross-level interactions.

Hypothesis $\mathbf{2 b} \mathbf{b} \mathbf{H} \mathbf{2 b})$. The relation of daily positive affect with job crafting will be stronger when resilience is low (vs. high).

Figure 1 depicts the effects hypothesized here. To test these hypotheses, we conducted a field survey adopting experience sampling methodology. We asked participants to provide daily reports of their positive affect and job crafting. Also, we measured participants' resources (i.e., LMX and resilience). We describe this study below. 


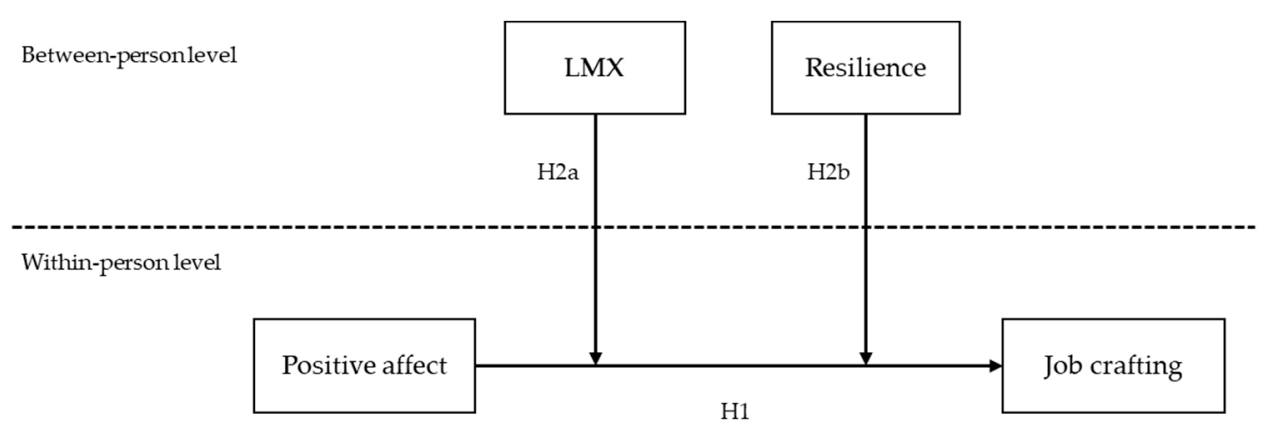

Figure 1. Proposed research model.

\section{Method}

\subsection{Sample and Procedures}

Participants in this study are employees working for 19 companies in South Korea. Participants were recruited through the authors, and they voluntarily responded to the survey. Respondents were sufficiently informed that the purpose of the survey. This survey contained the measures of our between-person level constructs and within-person level constructs. During the daily portion of the study, participants were sent one survey each day while they were at work for ten workdays. They were requested to fill in the diary surveys at the end of each workday. Also, authors sent reminder messages to participants. Most data was collected via face to face and a series of daily surveys.

The day the daily surveys started, we administered a survey to assess between individual variables. We distributed and collected surveys during working hours. We told participants that the surveys were designed to measure job attitudes and that their responses to the survey would be kept confidential. All these procedures were conducted in accordance with the ethical standards of the institutional research committee and with the 1964 Declaration of Helsinki and ethical standards with written informed consent from all subjects. The present study was approved by the Institutional Review Board (IRB) at Hanyang University. An initial sample of 130 full-time employees was selected for the study. Of these 115 individuals completed the initial survey, and 105 completed at least two days of surveys. Following other diary research, data from participants who completed less than two days of surveys were discarded [30]. In sum, usable data were available for 105 participants, and the number of data points obtained from the ten days of surveys was 1050. The within-person measures (i.e., positive affect, job crafting) response rate was $87 \%$. The 105 participants included full-time employees from organizations in South Korea and represented a variety of industries, including manufacturing, finance, and the service industry. They had worked at their current organization for an average of 2.74 years $(\mathrm{SD}=2.88)$. The sample was predominantly male $(57.1 \%)$. Most participants $(86.6 \%)$ had obtained at least a bachelor's degree.

\subsection{Measures}

All measures were assessed using a frequency scale ranging from 1 (never) to 5 (very often) except positive affect.

\subsubsection{Within-Person Measures}

Job crafting. We measured participants' daily job crafting using eight items developed by [14]. They consisted of three job crafting measure subscales (i.e., seeking resources, challenge resources, reducing demands). We have used at least two items for each dimension. Example statements include: "I ask colleagues for advice" and "I try to ensure that my work is emotionally less intense". The corresponding alpha coefficient was 0.80 . 
Positive affect. Participants responded to five items from a version of the Positive and Negative Affect Schedule scale [31]. Example items used in the scale were "excited" and "interested". The alpha coefficient was 0.87 .

\subsubsection{Between-Person Measures}

LMX. LMX was measured using 11 items adapted from [32]. Some sample items are "My supervisor would defend me to others in the organization if I made an honest mistake", "My supervisor would come to my defense if I were "attacked" by others". The alpha coefficient was 0.96 .

Resilience. Resilience was measured by four items adopted from [33]. Sample items are "I can get through difficult times at work because I've experienced difficulty before", "I usually take stressful things at work in stride". The alpha coefficient was 0.86 .

Control variables. We controlled for gender $(0=$ female, $1=$ male, industry $(0=$ others, $1=$ manufacturing business) in addition to the extraversion because of its potential to influence positive affect [34]. Extraversion was assessed using four items from International Personality Item Pool (IPIP; [35]). The alpha coefficient was 0.83 .

\subsection{Analytical Procedure}

We tested the robustness of the measurement model described by measures of positive affect, job crafting, LMX, and resilience with confirmatory analysis using item parcels for each construct (to reduce the number of indicators). The four factor model showed appropriate goodness-of-fit, $\chi^{2}=501.46, \mathrm{df}$ $=67, p=0.00$ (RMSEA $=0.08, \mathrm{CFI}=0.94, \mathrm{TLI}=0.91$ ) but a single-factor model did not fit the data well $(\mathrm{RMSEA}=0.15, \mathrm{CFI}=0.78, \mathrm{TLI}=0.68)$. Because of the nested nature of our data (daily variables nested individuals), we used hierarchical linear modeling (HLM; [36]). The time-varying variables are considered Level 1 variables because they are nested within each participant (Level 2). To ensure the appropriateness of multilevel modeling, we investigated whether systematic with-and between person variance existed in the variables. For positive affect, $36 \%$ of the variance was within individuals. There also substantial within-person variance in job crafting $(42 \%)$. Consequently, significant amounts of variance are left to be explained by within-person variations, justifying the multilevel approach. First, a null model was tested in which no predictors were entered. Next, model tested in which control variables were entered (Model 1). We tested the daily within-person level predictor (Model 2). Then, we introduced the moderators, followed by LMX and resilience (Model 3). Lastly, tested the cross level interaction of LMX and resilience (Model 4). All daily within-person level predictor was centered at between-person level's mean. Between-person level predictors were grand-mean centered. Also, as recommended by [37], these Level 1 variables were group-mean centered so as to control level 2 compounds.

\section{Results}

Presented in Table 1 are the means, standard deviations, and daily within-person level and between-person level correlations for the study variables.

Table 2 shows the result of the Hypotheses test. Hypothesis 1 looked at the effect of positive affect on job crafting. Result Table 2 shows a significant relationship between positive affect and job crafting $(\gamma=0.30, p<0.01)$. Thus, Hypothesis 1 was supported. Hypothesis 2 predicts that LMX moderates the relation between daily positive affect and job crafting. The effect of the interaction of LMX was significant $(\gamma=-0.19, p<0.01)$. Results indicate that those who were high in positive affect were more likely to experience job crafting when they have low level LMX. Thus Hypothesis 2 was supported. Also, we presented Figure 2. Figure 2 represented that the interaction effect was consistent with our expectation. Finally, resilience did not show a significant moderating effect on the positive affect-job crafting relationship, which lends no support to Hypothesis $3(\gamma=0.07, p=$ n.s.). 
Table 1. Descriptive Statistics and Intercorrelations.

\begin{tabular}{|c|c|c|c|c|c|c|c|c|}
\hline & $\mathbf{M}$ & SD & 1 & 2 & 3 & 4 & 5 & 6 \\
\hline \multicolumn{9}{|l|}{ Within-person Level } \\
\hline 1. Positive affect & 30.01 & 0.70 & & & & & & \\
\hline 2. Job crafting & 3.27 & 0.59 & $0.55^{* *}$ & & & & & \\
\hline \multicolumn{9}{|c|}{ Between-person Level } \\
\hline 3. Gender & 0.62 & 0.49 & & & & & & \\
\hline 4. Organization & 0.48 & 0.50 & & & 0.15 & & & \\
\hline 5. Extraversion & 3.37 & 0.80 & & & 0.19 & -0.05 & & \\
\hline 6. LMX & 3.52 & 0.80 & & & $0.25 *$ & 0.00 & 0.02 & \\
\hline 7. Resilience & 3.40 & 0.79 & & & $0.37^{* *}$ & 0.15 & $0.25 *$ & $0.57^{* *}$ \\
\hline
\end{tabular}

Within-person level $\mathrm{n}=1050$; Between-person level $\mathrm{n}=105$. Gender: $0=$ female, $1=$ male; Organization: $0=$ Others, $1=$ Manufacturing business. ${ }^{*} p<0.05,{ }^{* *} p<0.01$.

Table 2. The results of cross-level interaction effects using Hierarchical Linear Modeling.

\begin{tabular}{|c|c|c|c|c|}
\hline \multirow{2}{*}{ Independent Variable } & \multicolumn{4}{|c|}{ Dependent Variable: Job Crafting } \\
\hline & Model 1 & Model 2 & Model 3 & Model 4 \\
\hline \multicolumn{5}{|l|}{ Within-person level } \\
\hline Positive Affect & & $0.30(0.03) * * *$ & $0.30(0.05) * * *$ & $0.30(0.05) * * *$ \\
\hline \multicolumn{5}{|l|}{ Between-person level } \\
\hline Gender & $0.04(0.08)$ & $0.04(0.09)$ & $0.05(0.08)$ & $0.05(0.08)$ \\
\hline Organization & $-0.09(0.08)$ & $-0.09(0.08)$ & $-0.05(0.08)$ & $-0.05(0.08)$ \\
\hline Extraversion & $0.08(0.05)$ & $0.08(0.05)$ & $0.13(0.05) *$ & $0.13(0.05)^{* *}$ \\
\hline Positive Affect & $0.48(0.07)^{* * *}$ & $0.48(0.07) * * *$ & $0.51(0.09)^{* * *}$ & $0.51(0.09)^{* * *}$ \\
\hline LMX & & & $0.16(0.06)^{* *}$ & $0.17(0.06) * *$ \\
\hline Resilience & & & $-0.18(0.07) *$ & $-0.19(0.07) *$ \\
\hline \multicolumn{5}{|l|}{ Cross-level interaction effects } \\
\hline Positive Affect ${ }^{*}$ LMX & & & & $-0.19(0.07)^{* *}$ \\
\hline Positive Affect ${ }^{*}$ Resilience & & & & $0.07(0.08)$ \\
\hline Pseudo $R^{2}$ & 0.26 & 0.25 & 0.31 & 0.31 \\
\hline
\end{tabular}

Note. Within-person level $\mathrm{n}=1050$; Between-person level $\mathrm{n}=105$. All day level predictor was centered at between-individual level's mean. Between-individual level predictors were grand-mean centered. Entries are estimates of the fixed effects with standard errors. Pseudo R2 is computed as the proportional reduction in mean squared prediction error [38]. Gender: $0=$ Female, $1=$ male; Organization: $0=$ Others, $1=$ Manufacturing business. ${ }^{*} p<0.05,{ }^{* *} p<0.01,{ }^{* * *} p<0.001$.

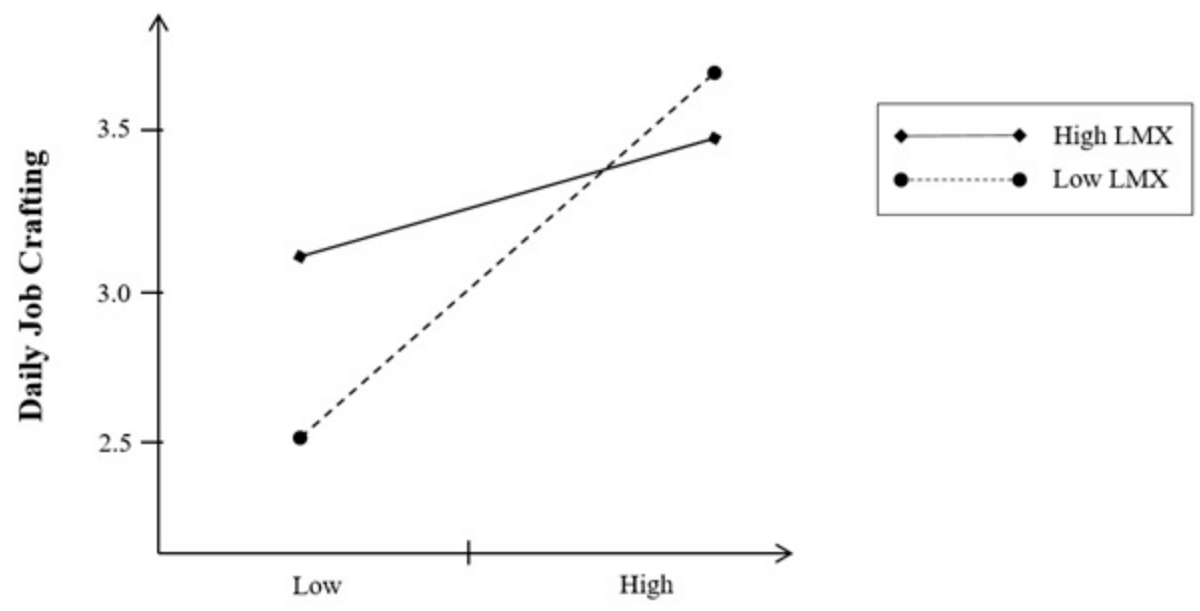

Daily Positive Affect

Figure 2. The cross level moderating effect of LMX. 


\section{Discussion}

\subsection{Theoretical and Practical Implications}

The present study has multiple theoretical implications. First, this study found that the overall daily positive affect of a work place is a meaningful predisposing factor to job crafting. Previous studies have thus far shown that daily self-efficacy, job autonomy, and resources are the factors that predispose daily job crafting $[5,6,39]$. Considering that job crafting is a phenomenon caused by internal motivation of employees [2], the present study has a theoretical significance in that it is the first study that empirically confirmed the importance of experiencing positive affect in order to facilitate daily job crafting activities of employees. This finding is in line with previous studies, which suggest that positive affect leads to an employee's positive outcome such as improved organizational citizenship behavior, job performance, and job satisfaction $[15,40]$. Taken together, we contribute to the development of daily job crafting research by examining which workplace conditions promote daily job crafting. Furthermore, this result suggests that daily positive affect is associated with energy that is enacting to proactive behavior or positive outcomes. Second, we empirically confirmed the cross level moderating effect of LMX in the relationship between positive affect and job crafting. These results suggest that job crafting can be triggered by strong internal motivation, such as the experience of daily positive affect, since the influence of an individual's low level of social resource (e.g., LMX), which has accumulated external rewards called trust from the leader. To that extent, the job crafting experience of employees who have an abundance of resources is relatively less influenced by daily affect. Third, the moderating effect of resilience on the relationship between daily positive affect and job crafting has not been verified in this research. This can be interpreted as follows. Based on the previous research, the effect of resilience usually occurs when members face a negative situation. Since, in our research, positive affect and job crafting are a continuous process of increasing employee's resource and motivation, the effect of resilience would not have been significant. A final contribution of the present study is the diary design. By measuring the study variables at the within-person level and the use of experience sampling methodology, this diary study provided to a better understanding of the dynamic antecedents of job crafting in employees' day-to-day experience of work [41].

There are several potentially important practical implications of our research. From the results of the study, it was confirmed that what influences daily job crafting is positive affect experienced in the workplace. Therefore, managers of an organization should manage in such a way that members can have a positive experience when performing their tasks. According to affective event theory, event is a distal antecedent to arousal affect in workplace [7], managers should employ practices that events which enhance the positive affect of employees. Second, particularly, in the case of members showing a low level of social resource, that is, a low level of LMX, daily positive experience can be even more important. Therefore, there is a need to provide many opportunities for employees that allow for positive experiences while performing challenging tasks or achieving goals. At the same time, employees should learn how they could keep up the positive emotion at workplace because the positive emotion is a key contributor for crafting their task proactively.

\subsection{Limitations and Future Directions}

This study has some limitations. First, this study could not measure the fluctuations of emotional change that can occur in a single day because there was only one measurement each day. Although the effect of overall positivity of individuals was removed through the control variables, future studies will need to be conducted to control the positive affect and job crafting of the existing individual through more than one measurement per day, and to have the variation amount, which will be shown afterwards, as the target to be analyzed, taking into consideration the limitations of this study. Second, our research revealed the moderating effect in the relationship between positive affect and job crafting. Other studies must inspect the moderating effects of variables that can further weaken or strengthen the relationship between daily positive affect and job crafting. In the present study, individual factors such 
as social and psychological resources were examined as moderators. In addition to these factors, further studies should consider other factors, including job characteristics, personality, or organizational characteristics such as perceived organizational support, and climate, as alternative moderators [4]. These efforts are expected to contribute to the expansion of future research on job crafting. Third, in this study we only considered the effect of a positive affect on job crafting because we concentrated on verifying antecedents of job crafting on positive organizational perspective. We suggest examining the role of negative affect in future research. Fourth, although we tried to explain the relationship between positive affect and job crafting, we were unable to determine causality since ours is a correlational study. We recommend that future researchers consider another method to solve this issue. Fifth, the data was single-sourced and self-reported. Although self-reports of all variables (e.g., positive affect, job crafting and LMX) are quite appropriate, proactive behaviors are typically measured with others. Thus, future researchers should consider a more cross-sectional design

\section{Conclusions}

In conclusion, our study expands knowledge on the day level antecedents and boundary condition of job crafting. Thereby, we contribute to both research and organizational practice with regard to regard to job crafting by showing how job crafting can be facilitated.

Author Contributions: Conceptualization, N.K. and M.-s.K.; Methodology, N.K.; Writing Original Draft, N.K. and M.K.; Writing Review \& Editing, N.K. and M.K.; Project Administration, M.-s.K.; Funding Acquisition, M.-s.K.

Funding: This work was supported by the Ministry of Education of the Republic of Korea and the National Research Foundation of Korea (NRF-2017S1A5A2A01027245).

Conflicts of Interest: The authors declare no conflict of interest.

\section{References}

1. Grant, A.M.; Parker, S.K. 7 redesigning work design theories: The rise of relational and proactive perspectives. Acad. Manag. Ann. 2009, 3, 317-375. [CrossRef]

2. Wrzesniewski, A.; Dutton, J.E. Crafting a job: Revisioning employees as active crafters of their work. Acad. Manag. Rev. 2001, 26, 179-201. [CrossRef]

3. Bruning, P.F.; Campion, M.A. A Role-resource Approach-avoidance Model of Job Crafting: A Multimethod Integration and Extension of Job Crafting Theory. Acad. Manag. J. 2018, 61, 499-522. [CrossRef]

4. Rudolph, C.W.; Katz, I.M.; Lavigne, K.N.; Zacher, H. Job crafting: A meta-analysis of relationships with individual differences, job characteristics, and work outcomes. J. Vocat. Behav. 2017, 102, 112-138. [CrossRef]

5. Petrou, P.; Demerouti, E.; Peeters, M.C.; Schaufeli, W.B.; Hetland, J. Crafting a job on a daily basis: Contextual correlates and the link to work engagement. J. Organ. Behav. 2012, 33, 1120-1141. [CrossRef]

6. Tims, M.; Bakker, A.B.; Derks, D. Daily job crafting and the self-efficacy-performance relationship. J. Manag. Psychol. 2014, 29, 490-507. [CrossRef]

7. Weiss, H.M.; Cropanzano, R. Affective events theory: A theoretical discussion of the structure, causes and consequences of affective experiences at work. In Research in Organizational Behavior; Staw, B.M., Cummings, L.L., Eds.; JAI Press: Stamford, CT, USA, 1996; Volume 18, pp. 1-74.

8. Luthans, F.; Youssef, C.M. Emerging positive organizational behavior. J. Manag. 2007, 33, 321-349. [CrossRef]

9. Hobfoll, S.E. Conservation of resources: A new approach at conceptualizing stress. Am. Psychol. 1989, 44, 513-524. [CrossRef]

10. Grant, A.M.; Ashford, S.J. The dynamics of proactivity at work. Res. Organ. Behav. 2008, 28, 3-34. [CrossRef]

11. Griffin, M.A.; Neal, A.; Parker, S.K. A new model of work role performance: Positive behavior in uncertain and interdependent contexts. Acad. Manag. J. 2007, 50, 327-347. [CrossRef]

12. Laurence, G.A.; Fried, Y.; Yan, W.; Li, J. Enjoyment of Work and Driven to Work as Motivations of Job Crafting: Evidence from Japan and China. Jpn. Psychol. Res. 2019. [CrossRef]

13. Bakker, A.B.; Tims, M.; Derks, D. Proactive personality and job performance: The role of job crafting and work engagement. Hum. Relat. 2012, 65, 1359-1378. [CrossRef] 
14. Tims, M.; Bakker, A.B.; Derks, D. Development and validation of the job crafting scale. J. Vocat. Behav. 2012, 80, 173-186. [CrossRef]

15. Lyubomirsky, S.; King, L.; Diener, E. The benefits of frequent positive affect: Does happiness lead to success? Psychol. Bull. 2005, 131, 803-855. [CrossRef] [PubMed]

16. Ilies, R.; Scott, B.A.; Judge, T.A. The interactive effects of personal traits and experienced states on intraindividual patterns of citizenship behavior. Acad. Manag. J. 2006, 49, 561-575. [CrossRef]

17. Judge, T.A.; Heller, D.; Mount, M.K. Five-factor model of personality and job satisfaction: A meta-analysis. J. Appl. Psychol. 2002, 87, 530-541. [CrossRef]

18. Beal, D.J.; Ghandour, L. Stability, change, and the stability of change in daily workplace affect. J. Organ. Behav. 2011, 32, 526-546. [CrossRef]

19. Cacioppo, J.T.; Gardner, W.L.; Berntson, G.G. The affect system has parallel and integrative processing components: Form follows function. J. Personal. Soc. Psychol. 1999, 76, 839-855. [CrossRef]

20. Fritz, C.; Sonnentag, S. Antecedents of day-level proactive behavior: A look at job stressors and positive affect during the workday. J. Manag. 2009, 35, 94-111. [CrossRef]

21. George, J.M.; Brief, A.P. Feeling good-Doing good: A conceptual analysis of the mood at work-organizational spontaneity relationship. Psychol. Bull. 1992, 112, 310-329. [CrossRef]

22. Rothbard, N.P.; Wilk, S.L. Waking up on the right or wrong side of the bed: Start-of-workday mood, work events, employee affect, and performance. Acad. Manag. J. 2011, 54, 959-980. [CrossRef]

23. Fredrickson, B.L. The role of positive emotions in positive psychology-The broaden-and-build theory of positive emotions. Am. Psychol. 2001, 56, 218-226. [CrossRef]

24. Butts, M.M.; Becker, W.J.; Boswell, W.R. Hot buttons and time sinks: The effects of electronic communication during nonwork time on emotions and work-nonwork conflict. Acad. Manag. J. 2015, 58, 763-788. [CrossRef]

25. Liden, R.C.; Erdogan, B.; Wayne, S.J.; Sparrowe, R.T. Leader-member exchange, differentiation, and task interdependence: Implications for individual and group performance. J. Organ. Behav. 2006, 27, 723-746. [CrossRef]

26. Erdogan, B.; Kraimer, M.L.; Liden, R.C. Work value congruence and intrinsic career success: The compensatory roles of leader-member exchange and perceived organizational support. Pers. Psychol. 2004, 57, 305-332. [CrossRef]

27. Ng, T.W.; Sorensen, K.L. Toward a further understanding of the relationships between perceptions of support and work attitudes: A meta-analysis. Group Organ. Manag. 2008, 33, 243-268. [CrossRef]

28. Lazarus, R.S. From psychological stress to the emotions: A history of changing outlooks. Ann. Rev. Psychol. 1993, 44, 1-21. [CrossRef] [PubMed]

29. Avey, J.B.; Luthans, F.; Smith, R.M.; Palmer, N.F. Impact of positive psychological capital on employee well-being over time. J. Occup. Health Psychol. 2010, 15, 17-28. [CrossRef]

30. Dimotakis, N.; Scott, B.A.; Koopman, J. An experience sampling investigation of workplace interactions, affective states, and employee well-being. J. Organ. Behav. 2011, 32, 572-588. [CrossRef]

31. Watson, D.; Clark, L.A.; Tellegen, A. Development and validation of brief measures of positive and negative affect: The PANAS scales. J. Personal. Soc. Psychol. 1988, 54, 1063-1070. [CrossRef]

32. Liden, R.C.; Maslyn, J.M. Multidimensionality of leader-member exchange: An empirical assessment through scale development. J. Manag. 1998, 24, 43-72. [CrossRef]

33. Luthans, F.; Avolio, B.J.; Avey, J.B.; Norman, S.M. Positive psychological capital: Measurement and relationship with performance and satisfaction. Pers. Psychol. 2007, 60, 541-572. [CrossRef]

34. Larsen, R.J.; Ketelaar, T. Personality and susceptibility to positive and negative emotional states. J. Personal. Soc. Psychol. 1991, 61, 132-140. [CrossRef]

35. Goldberg, L.R. A broad-bandwidth, public domain, personality inventory measuring the lower-level facets of several five-factor models. In Personality Psychology in Europe; Mervielde, I., Deary, F., De Fruyt, P., Ostendorf, F., Eds.; Tilburg University Press: Tilburg, The Netherlands, 1999; pp. 7-28.

36. Raudenbush, S.W.; Bryk, A.S. Hierarchical Linear Models: Applications and Data Analysis Methods, 2nd ed.; Sage: Thousand Oaks, CA, USA, 2002.

37. Hofmann, S.A.; Griffin, M.A.; Gavin, M.B. The application of hierarchical linear modeling to organizational research. In Multilevel Theory, Research, and Methods in Organizations: Foundations, Extensions, and New Directions; Klein, K., Kozlowski, S., Eds.; Jossey-Bass: San Francisco, CA, USA, 2000; pp. 75-170. 
38. Snijders, T.A.B.; Bosker, R.J. Multilevel Analysis: An Introduction to Basic and Advanced Multi-Level Modeling; Sage: Thousand Oaks, CA, USA, 1999.

39. Bakker, A.B.; Costa, P.L. Chronic job burnout and daily functioning: A theoretical analysis. Burn. Res. 2014, 1, 112-119. [CrossRef]

40. Deluga, R.J.; Masson, S. Relationship of resident assistant conscientiousness, extraversion, and positive affect with rated performance. J. Res. Personal. 2000, 34, 225-235. [CrossRef]

41. Bolger, N.; Davis, A.; Rafaeli, E. Diary methods: Capturing life as it is lived. Annu. Rev. Psychol. 2003, 54, 579-616. [CrossRef] [PubMed]

(C) 2019 by the authors. Licensee MDPI, Basel, Switzerland. This article is an open access article distributed under the terms and conditions of the Creative Commons Attribution (CC BY) license (http://creativecommons.org/licenses/by/4.0/). 